THE ROLE OF PARENT-CHILD RELATIONSHIP IN THE

\title{
DEVELOPMENT OF ALCOHOLISM
}

\author{
ANITA SHARMA $^{1} \&$ JYOTI SHARMA ${ }^{2}$ \\ ${ }^{I}$ Deputy Director, UGC-HRDC \& Associate Professor, (HOD) Department of Psychology, \\ HPU, Shimla, Himachal Pradesh, India \\ ${ }^{2}$ Research Scholar, Department of Psychology, HPU, Shimla, Himachal Pradesh, India
}

The objective of the present study was to investigate the relationship between the parent-child relationship and alcoholism. The sample comprised of 180 alcoholics sample. For this 180 subjects (alcoholics) were taken from urban and rural areas (90 each) belonging to upper, middle and lower class (60 each) from two districts of Himachal Pradesh (Kinnaur and Shimla). Results of the study revealed that the parent-child relationship explained a significant amount of variance in alcoholism. The main findings point out to the following facts: In urban sample, rejecting fathers has significantly contributed $4 \%\left(r=.287^{* *}, p<.01\right)$ of variance in alcoholism, whereas, in rural sample, protecting fathers $(5 \% ; r=-.289 * *, p<.01)$, rejecting fathers $(5 \% ; r=.276 * *, p<.01)$ and loving fathers $(3 \% ; r=-.209 *$, $p<.05)$ have emerged as the significant predictors contributing $13 \%$ of variance in alcoholism. In upper class sample, protecting fathers $(20 \% ; r=-.446 * *, p<.01)$, loving fathers $(12 \% ; r=-.358 * *, p<.01)$, symbolic rewards by fathers $(5 \%$; $r=-.329 * *, p<.01)$ and neglecting fathers $(4 \% ; r=.317 * *, p<.01)$ have significantly contributed $41 \%$ of variance in alcoholism. In middle-class sample, rejecting fathers have significantly contributed $4 \%(r=.292 \%, p<.05)$ of the variance in alcoholism. In lower class sample, object punishment $(5 \% ; r=-.302 * *, p<.01)$ and neglecting mothers $(3 \% ; r=.277 * p<.05)$ have significantly contributed $8 \%$ of variance in alcoholism, whereas, in lower class sample, symbolic rewards $\left(r=-.221^{*}, p<.05\right)$ given by mothers is also negatively and significantly correlated with alcoholism, but in the regression analysis, it has failed to open its account. Thus, it can be concluded that the parent-child relationship plays a vital role in alcoholism.
\end{abstract}

KEYWORDS: Alcoholism \& Parent-Child Relationship

Received: Aug 20, 2018; Accepted: Sep 10, 2018; Published: Oct 31, 2018; Paper Id.: IJHRMRDEC20185

\section{INTRODUCTION}

Alcohol is one of the most addictive substances. It is fully legal for use by adults and readily available and widely abused substance. The younger the age at which young people start to drink and more likely they are to become regular drinkers in adulthood. Alcoholism is a condition in which an individual loses control over his alcohol intake in that he is constantly unable to refrain from drinking once he begins (Jhonson, Bransford, \& Solomon, 1973) and according to WHO an alcoholic is an excessive drinker whose dependence upon alcohol has reached such a degree that it results in a noticeable mental disturbance or an interference with his bodily and mental health, his interpersonal relations and his smooth social and economic functioning or one who shows the early signs of such developments. Alcoholism is characterized by an increased tolerance and physical dependence on alcohol affecting an individual's ability to control alcohol consumption safely and can't stop drinking (Hoffman, \& Tabakoff, 1996). Alcoholism has no one single cause. There are various causes of alcoholism i. e., 
genetic, psychological, social and cultural factors. An Environment is a main cause of alcoholism. Peer pressure, family environment and parent-child relationship are very important factors for alcoholism. They can either serve as a protective factor or a risk factor (Atkins, Oman, Vesely, Aspy, \& McLeroy, 2002). A family is the most important part of society. It is the first and the most immediate social environment to which a child is exposed. A favorable home environment constitutes of good parent-child relationship. Home is one of the most important sources to develop one's personality. This is because the members of the family constitute the child's first environment and are the most significant people during the early and formative years. From contacts with family members, children lay the foundations for attitudes towards people, things and life in general. Person's personality is strongly influenced by parents. Parent-child relationship refers to parentchild appraisals of the quality of the relationship between them, characterized by parental behaviors which give evidence of a warm and supporting relationship. Sometimes this construct is measured as a negative parent-child relationship expressed in rejection, criticizing ideas frequently, having frequent arguments or withholding of affection (Maccoby, 1992 and Wood, McLeod, Sigman, Hwang, \& Chu, 2003). Alcoholic parents serve as a role model for their children to drink. Alcoholics have grown up in an environment where their parents and older siblings drink and so they drink in order to look and act like them. Parental attitudes have a strong impact not only on family relationships but also on the attitudes and behavior of children towards alcoholism. Parental monitoring is commonly attributed as an important protective factor against risky adolescent behavior (Lac \& Crano, 2009). A good parent-child relationship reduces the probability of highrisk behavior like alcohol abuse, drug dependence, antisocial activities, and delinquent behavior, whereas, poor parentchild relationship increases the possibility of high-risk behavior. The experience of maltreatment in the home, high level of family tension or conflict is a risk factor for alcoholism. Negative relationship with parents decreases individual's wellbeing. A negative parent-child relationship is related to externalizing (such as aggression and delinquent behaviour) and internalizing problems (such as depression and anxiety) (Allen, Porter, McFarland, McElhaney \& Marsh, 2007, Brumariu \& Kerns, 2010 and Buist, Dekovic, Meeus \& VanAken, 2004) and also related to alcoholism. Individuals who perceive less parental support consume more alcohol. A Poor parent-child relationship can contribute to a stressful family environment. People with low family support have more alcohol and substance use (Wiegel, Sattler, Goritz, \& Diewald, 2015). Of parental factors associated with adolescent and emerging adult's alcohol use, the parent-child relationship is the most important relationship. Poor parenting creates a high risk of alcohol problems. Disturbed home environment and poor parenting are associated with anxiety, stress, depression, other mental disorders, and antisocial activities. Parental protection, love, and attachment are associated with lower levels of alcohol consumption among youth, whereas, parental rejection, neglecting, indifferent attitude, excessive demands and excessive control are significantly associated with later age of initiating alcohol use. A healthy parent-child relationship has a negative linear relationship with adolescent drinking (Ryan, Jorm \& Lubman, 2010 and Vakalahi, 2001). Low parental monitoring, low parental warmth, parental alcohol use and parent expectancies regarding their children's alcohol use are associated with higher incidence of adolescent binge drinking; whereas in early adulthood, low parental monitoring, low parental warmth, parent alcohol use, parent expectancies and underage consumption are associated with binge drinking.

Keeping in mind the findings of above-mentioned studies, the present study is an attempt to explore the role of parent-child relationship in alcoholism.

\section{HYPOTHESES}

- Protecting and loving behavior of parents will be negatively and significantly related to alcoholism. 
- Symbolic and object reward given by parents will be negatively and significantly related to alcoholism.

- $\quad$ Rejecting, demanding, neglecting and indifferent attitude of parents towards their children will be positively and significantly correlated with alcoholism.

- Symbolic and object punishment by parents given to their children will contribute negatively and significantly in alcoholism.

\section{METHOD}

\section{Sample}

The study has been conducted on a sample of alcoholics $(\mathrm{N}=180)$. First of all, they were subdivided into two comparable halves based on their area that forms $n=90$ in urban and another $n=90$ from the rural area. These subjects were further divided into three halves based on their economic class that comprised of $n=60$ from the upper class, middle-class $\mathrm{n}=60$ and another $\mathrm{n}=60$ from lower economic class groups. This made six conditions, in each condition 30 subjects were used thereby yielding a total sample of 180 subjects, age range between 25 to 45 years. Sampling technique was purposive.

\section{Design}

Correlational design was used to see the association between parent-child relationship and alcoholism. Further, regression analysis was carried out separately for urban/rural and upper/middle and lower class alcoholics samples to find out the best set of predictors of alcoholism.

\section{Tools}

\section{Alcohol, Smoking, Substance Involvement Scoring Test (ASSIST)}

To measure alcoholism, ASSIST was used in the present study. It contains 8 items relating to different situations. It is a brief screening questionnaire to find out peoples' involvement in alcohol, smoking, and substance. Each question in the ASSIST has a set of responses. Item number one has only two options in the form of 'yes' or 'no'. Whereas, item numbers from 2 to 5 have five options (Never: not used in the last 3 months, once or twice: 1 to 2 times in the last 3 months, monthly: 1 to 3 times in one month. Weekly: 1 to 4 times per week. Daily or almost daily: 5 to 7 days per week) and remaining three items i. e. item 6, 7 and 8 have three options (No, Never / Yes, but not in the past 3 months / Yes, in the past 3 months). Thus, the score range from 0 to 39. For alcohol scores received for questions 2 through 7 inclusive are added and the results from either Q1 or Q8 in this score are not included. For example, a score for alcohol would be calculated as Q2 + Q3 + Q4 + Q5 + Q6 + Q7. Alcoholic Beverages 0-10= Low, 11-26=Moderate and 27+ =High. Low scorers are at low risk of health and other problems from their current pattern of use. Moderate scorers are at risk of health and other problems from their current pattern of substance use. High scorers are at high risk of experiencing severe problems (health, social, financial, legal, relationship) as a result of their current pattern of use and are likely to be dependent. Higher the score, more vulnerable the person will be towards ASSIST. The test-retest reliability coefficient ranges from a high of.58 to. 90 .

\section{Parent-Child Relationship Scale (Rao, 1989)}

The parent-child relationship scale was developed by Nalini Rao in 1989. The scale measures the characteristic behavior of parents as experienced by their children. The data available on the items of the scale can be grouped into fairly universal dimensions of children's experience of family interaction with the two parent factor. This tool contains 100 items 
categorized into ten dimensions namely: protecting, symbolic punishment, rejecting, object punishment, demanding, indifferent, symbolic reward, loving, object reward and neglecting. Each respondent score the tool for both father and mother separately. The questionnaire consists of 100 items and it is a 5-point rating scale (1-rarely, 2-seldom, 3-sometimes, 4-quite often and 5-very often). Rating of this scale is a mode of five-point scale ranging from 'always' to 'very rarely' weighted 5, 4, 3, 2 and 1 on the scale points. The test-retest reliability coefficient ranged from.77 and to.87 for males' sample and.77 to. 87 for the females' sample over the sub-scales.

\section{RESULTS}

In the urban sample, Rejecting fathers correlated positively and significantly with alcoholism $\left(\mathrm{r}=.287^{* *}, \mathrm{p}<.01\right)$ (see Table-1 for more details). In regression analysis, only rejecting fathers emerged as a significant predictor of alcoholism and explained about $4 \%$ of the variance.

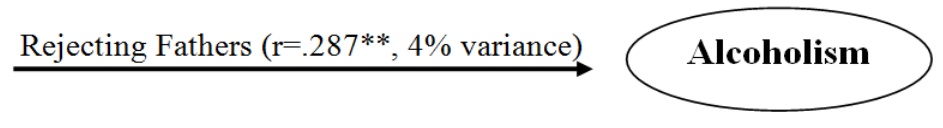

Figure 1

In rural sample, Protecting fathers $\left(\mathrm{r}=-.289^{* *}, \mathrm{p}<.01\right)$ and loving fathers $\left(\mathrm{r}=-.209^{*}, \mathrm{p}<.05\right)$ correlated significantly and negatively with alcoholism, whereas, rejecting fathers correlated significantly and positively with alcoholism ( $\left.\mathrm{r}=.276^{* *}, \mathrm{p}<.01\right)$ (see Table-1 for more details). In regression analysis, only protecting fathers (5\%), loving fathers (5\%) and rejecting fathers (3\%) emerged as significant predictors of alcoholism and explained $13 \%$ of the variance in totality.
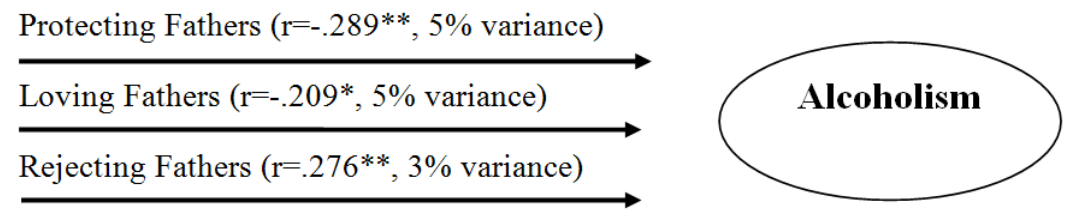

Figure 2

In upper class sample, Protecting fathers $\left(\mathrm{r}=-.446^{* *}, \mathrm{p}<.01\right)$, loving fathers $\left(\mathrm{r}=-.358^{* *}, \mathrm{p}<.01\right)$ and symbolic rewards by fathers $\left(\mathrm{r}=-.329^{* *}, \mathrm{p}<.01\right)$ correlated significantly and negatively with alcoholism, whereas, neglecting fathers $\left(\mathrm{r}=.292^{*}, \mathrm{p}<.05\right)$ correlated significantly and positively with alcoholism (see Table-1 for more details). In regression analysis, protecting fathers (20\%), loving fathers (5\%), symbolic rewards by fathers (12\%) and neglecting fathers (4\%) emerged as significant predictors of alcoholism and explained $41 \%$ of the variance in totality.
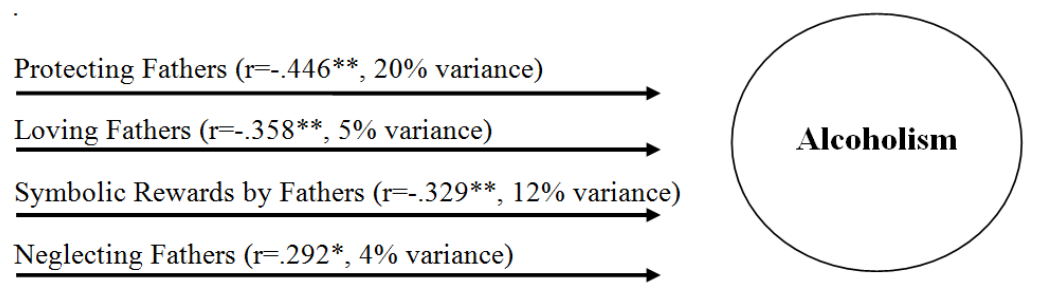

Figure 3

In middle-class sample, Rejecting fathers correlated significantly and positively with alcoholism $\left(\mathrm{r}=.292^{*}\right.$, $\mathrm{p}<.05$ ) (see Table-1 for more clarification). In regression analysis, rejecting fathers emerged as a significant predictor of alcoholism and explained about $4 \%$ of the variance. 


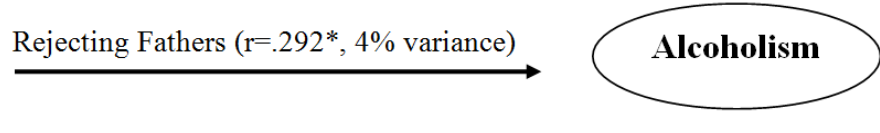

Figure 4

In lower class sample, Object punishment by fathers $(\mathrm{r}=-.302 * *, \mathrm{p}<.01)$ and symbolic rewards by mothers ( $\mathrm{r}=-$ $\left..221^{*}, \mathrm{p}<.05\right)$ correlated significantly and negatively with alcoholism, whereas, neglecting mothers $\left(\mathrm{r}=.277^{*}, \mathrm{p}<.05\right)$ correlated significantly and positively with alcoholism (see Table-1 for more details). In regression analysis, object punishment $(5 \%)$ and neglecting mothers (3\%) emerged as significant predictors of alcoholism and explained a total $8 \%$ of the variance.

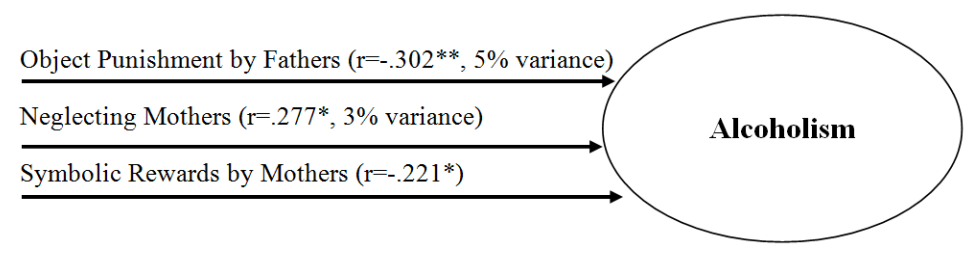

Figure 5

Table 1: Correlates of Alcoholism: Role of Parent-Child Relationship

\begin{tabular}{|c|c|c|c|c|c|c|}
\hline \multicolumn{2}{|c|}{ Variables } & $\begin{array}{l}\text { Urban } \\
(\mathrm{N}=90)\end{array}$ & $\begin{array}{c}\text { Rural } \\
(\mathrm{N}=90)\end{array}$ & $\begin{array}{c}\text { Upper Class } \\
(\mathrm{N}=60)\end{array}$ & $\begin{array}{l}\text { Middle Class } \\
(\mathrm{N}=60)\end{array}$ & $\begin{array}{c}\text { Lower Class } \\
(\mathrm{N}=60)\end{array}$ \\
\hline \multirow{2}{*}{ Protecting } & Fathers & - & $-.289 * *$ & $-.446 * *$ & - & - \\
\hline & Mothers & - & - & - & - & - \\
\hline \multirow{2}{*}{$\begin{array}{l}\text { Symbolic } \\
\text { Punishment }\end{array}$} & Fathers & - & - & - & - & - \\
\hline & Mothers & - & - & - & - & - \\
\hline \multirow{2}{*}{ Rejecting } & Fathers & $.287 * *$ & $.276^{* *}$ & - & $.292 *$ & - \\
\hline & Mothers & - & - & - & - & - \\
\hline \multirow{2}{*}{$\begin{array}{l}\text { Object } \\
\text { Punishment }\end{array}$} & Fathers & - & - & - & - & $-.302 * *$ \\
\hline & Mothers & - & - & - & - & - \\
\hline \multirow{2}{*}{ Demanding } & Fathers & - & - & - & - & - \\
\hline & Mothers & - & - & - & - & - \\
\hline \multirow{2}{*}{ Indifferent } & Fathers & - & - & - & - & - \\
\hline & Mothers & - & - & - & - & - \\
\hline \multirow{2}{*}{$\begin{array}{l}\text { Symbolic } \\
\text { Rewards }\end{array}$} & Fathers & - & - & $-.329 * *$ & - & - \\
\hline & Mothers & - & - & - & - & $-.221 *$ \\
\hline \multirow{2}{*}{ Loving } & Fathers & - & $-.209 *$ & $-.358 * *$ & - & - \\
\hline & Mothers & - & - & - & - & - \\
\hline \multirow{2}{*}{$\begin{array}{l}\text { Object } \\
\text { Rewards }\end{array}$} & Fathers & - & - & - & - & - \\
\hline & Mothers & - & - & - & - & - \\
\hline \multirow{2}{*}{ Neglecting } & Fathers & - & - & $.317 * *$ & - & - \\
\hline & Mothers & - & - & - & - & $.277 *$ \\
\hline
\end{tabular}

\section{DISCUSSIONS}

A negative parent-child relationship is positively related to alcoholism. Alcoholic's families have a poorer parentchild relationship. The results have revealed that protecting and loving attitudes of parents are negatively associated with 
alcohol use. Protecting and loving attitudes of parents protect their children from the use of alcohol. Protective behavior protects their children from bad habits. Protecting, loving and less demanding parents are more connected and supportive. Parental warmth and protective involvement increases self-esteem and reduces the use of alcohol. Protective and loving parents' children are less likely to yield to peer-pressure or engage in risky behavior (i. e., alcoholism, anti-social activities, crime etc.) because of their emotional bond. Not only this, the defending attitude of the parents expressed in the form of guarding, sheltering and shielding the child from threatening situation gives the sense of security and the child may feel secure, more confident that someone is always there for them to shield from the harmful situation which in turn gives the sense of parental support and protect them from stress, anxiety, negative emotions and alcohol involvement. Adolescents who are aware that their parents would be upset with them if they drink are less likely to do so, highlighting the importance of communication between parents and teen as a protective measure against underage alcohol use (Foley, Altman, Durant, \& Wolfson, 2004).

The results have further revealed that symbolic reward and object punishment by parents are negatively correlated with alcoholism. Punishment and rewards both are part of the parental monitoring. Reward (reinforcement) is the strengthening and punishment is the weakening of behavior especially when both are in operation. Effective parental monitoring and supervision are negatively associated with alcoholism. Symbolic reward given by parents is negatively correlated with alcoholism. Rewards from parents are provided to a child after the child has behaved well. Reward gives the sense of satisfaction to the children for their deeds and makes them happy. This kind of feeling is good for mental health and protect from future involvement in alcoholism. Punishment helps to make children obedient, respectful and polite. Punishment protects children from bad habits. The purpose of punishment is to stop a child from doing what parents don't want. But corporal punishment has a negative impact on the parent-child relationship which leads to alcoholism. Corporal punishment or physical punishment is a punishment intended to cause physical pain on a person. It is most often used where there is a substantial disparity of power between punisher and punished. Childhood physical punishment has been associated with a greater occurrence of drinking problems and alcohol use disorder (Afifi, Brownridge, Cox, \& Sareen, 2006 and Kaur, 2004). Corporal punishment evokes a feeling of fear, stress, anxiety, anger, and depression. If the parents show annoyance with the child either symbolically or physically without understanding or listening to them, then under such situations children may feel that their parents don't love and care them, then under such situations, children may feel that their parents don't love and care for them. They may develop the feeling of rejection and devalue themselves which may lead to psychological problems. Negative parent-child relationship leads children to avoid their parents and more likely to yield to peer pressure. Parents' corporal punishments disrupt the parent-child relationship (Azrin, Hake, Holz, \& Hutchinston, 1965 and Azrin \& Holz, 1966). Individual who suffered from harsh physical punishments were more likely to resort to alcohol use, whereas, right punishment prevent the onset of alcohol use. Thus, on the basis of the results of the present study, the hypothesis that "protecting and loving behavior of parents, object punishment and symbolic reward by parents would be negatively and significantly correlated with alcoholism" is accepted and confirmed.

The results have revealed that rejecting and neglecting behavior of parents is positively associated with alcohol use. The rationale could be offered in terms of the fact that rejecting and neglecting attitude of the parents might leave the child to devalue him. Rejecting behavior means renouncing the child in aversion. Neglecting behavior means a careless slighting treatment indicated in the accustomed omission and deliberate disregard towards the child which might leave the child to devalue himself in disdain. Rejecting and neglecting parents exert low control and discipline as well as low warmth and responsiveness. They show no interest at all in a child's behavior. Parents make few demands from their 
children and they are often indifferent, rude and unconcerned. These parents have little emotional involvement with their children. An adolescent who perceive their parents as uninvolved use more drugs and alcohol use (Adalbjarnardottir $\boldsymbol{\&}$ Hafsteinsson, 2001). Thus, on the basis of the present study, the hypothesis that "parental rejecting and neglecting behavior would be positively and significantly correlated with alcoholism" is accepted and confirmed.

The results of the study suggest that there is a significant correlation between parent-child relationship and alcoholism. Alcoholics scoring high in rejecting and neglecting parents are associated with higher risk of developing alcohol problems. Whereas, alcoholics scoring high in protecting and loving parents, symbolic rewards and object punishment by parents are associated with lower risk of developing alcohol abuse.

\section{CONCLUSIONS}

In the present study, protecting parents, loving parents, symbolic rewards by parents, object punishment by parents, rejecting and neglecting behavior of parents are the major and contributing factors in alcoholism. Protecting and loving behavior of parents, symbolic rewards and object punishment given by parents are protective factors of alcohol use, whereas, rejecting and neglecting behavior of parents are risk factors of alcohol use. In sum, it can be suggested and can be seen that negative parent-child relationship sows the seeds for alcoholism and other kinds of drug usage in the life of an individual. Neglecting and rejecting parental attitude play a pivotal role in the usage of alcoholic beverages. Hence, parents should provide a congenial atmosphere at home with an encouraging and positive attitude for the all-round development personality of their children.

\section{REFERENCES}

1. Adalbjarnardottir, S., \& Hafsteinsson, L. G. (2001). Adolescents' perceived parenting styles and substance use: Concurrent and longitudinal analyses. Journal of Research on Adolescence, 11, 401-23.

2. Afifi, T. O., Brownridge, D. A., Cox, B. J., \& Sareen, J. (2006). Physical punishment, childhood abuse and psychiatric disorders. Child Abuse and Neglect, 30, 1093-103.

3. Allen, J. P, Porter, M. R., MCFarlend, F. C., McElhaney, K. B., \& Marsh, P. A. (2007). The relation of attachment security to adolescents' paternal and peer relationships, depression and externalizing behaviour. Child Development, 78, 1222-39.

4. Atkins, L. A., Oman, R. F., Vesely, S. K., Aspy, C. B., \& McLeroy, K. (2002). Adolescent tobacco use: The protective effects of developmental assets. American Journal of Health Promotion, 16(4), 198-205.

5. Azrin, N. H., \& Holz, W. C. (1966). In W. K. Honig (Ed.), Operant behaviour: Areas of research and application. New York: Appleton-Cantury-Crofts.

6. Azrin, N. H., Hake, D. F., Holz, W. C., \& Hutchinston, R. R. (1965). Motivational aspects of escape from punishment. Journal of the Experimental Analysis of Behaviour, 8(1), 31-44.

7. Brumariu, L. E., \& Kerns, K. A. (2010). Parent-child attachment and internalizing symptoms in childhood and adolescence: A review of empirical findings and future directions. Development and Psychopathology, 22, 177-203.

8. Buist, K. L., Dekovic, M., Meeus, W., \& Van Aken, M. A. (2004). The reciprocal relationship between early adolescent attachment and internalizing and externalizing problem behaviour. Journal of Adolescence, 23(3), 251-66.

9. Foley, K. L., Altman, D., Durant, R. H., \& Wolfson, M. (2004). Adults' approval and adolescents' alcohol use. Journal of Adolescent Health, 35(4), 7-26. 
10. Hoffman, P. L., \& Tabakoff, B. (1996). Alcohol dependence: A Commentary on mechanisms. Alcohol, 31(4), 333-40.

11. Jhonson, M. K., Bransford, J. D., \& Solomon, S. K. (1973). Memory for tacit implications of sentences. Journal of Experimental Psychology, 98(1), 203.

12. Kaur, B. J. (2004). To study parent-child relationship and its effect on child's adjustment and academic achievement. M. Phil. Dissertation. Himachal Pradesh University, Shimla.

13. Lac, A., \& Crano, W. D. (2009). Monitoring matters: Meta-analytic review reveals the reliable linkage of parental monitoring with adolescent marijuana use. Perspectives on Psychological Science, 4, 578-86.

14. Maccoby, E. E. (1992). The role of parents in the socialization of children: An historical overview. Developmental Psychology, 33, 1006-17.

15. Rao, N. (1989). Manual for Parent-child Relationship Scale. National Psychological Corporation, Agra.

16. Ryan, S. M., Jorm, A. F., \& Lubman, D. I. (2010). Parenting factors associated with reduced adolescence alcohol use: A systematic review of longitudinal studies. Australian and New Zealand Journal of Psychiatry, 774-83.

17. Owoseni, O. O., Ofoegbu, O. E., \& Akanbi, P. A. Exploring The Relationship Between Strategic Human Resource Management (Shrm) And Perceived Organizational Performance In Nigeria.

18. Vakalahi, H. F. (2001). Adolescent substance use and family based risk and protective factors: A literature review. Journal of Drug Education, 31(1), 29-46.

19. WHO (2001). The Alcohol, Smoking and Substance Involvement Screening Test (ASSIST); Development, reliability and feasibility. Addiction, 97(9), 1183-94.

20. Wiegal, C., Sattler, S., Goritz, A. S., \& Diewald, M. (2015). Work related stress and cognitive enhancement among university teachers. Anxiety, Stress and Coping, 29, 100-17.

21. Wood, J. J., McLeod, B. D., Sigman, M., Hwang, W. C., \& Chu, B. C. (2003). Parenting and childhood anxiety: Theory, empirical findings and future directions. Journal of Child Psychology and Psychiatry, 44, 134-51. 